\title{
Subclinical Neurotoxicity of Mercury Vapor Revealed by a Multimodality Evoked Potential Study of Chloralkali Workers
}

\author{
Yang-Chyuan Chang, MD, Ching-ying Yeh, MPh, and \\ Jung-Der Wang, MD, DSC
}

\begin{abstract}
Pattern visual, brainstem auditory, and somatosensory evoked potential (EP) studies were performed on 26 chloralkali workers. The intensity of mercury vapor exposure in these workers was estimated from the individual working history. Mercury levels in blood, urine, and hair were determined with atomic absorption spectrometry. The EP findings were compared with those from individually matched normal subjects. In brainstem auditory and somatosensory EP studies, prolonged neural conduction times in the central nervous system (CNS) were found in workers exposed to mercury vapor. In the pattern visual EP study, mercury workers had higher interpeak amplitudes. Findings of this study suggested that chronic exposure to mercury vapor would affect the CNS functions. A multimodality EP study is a useful adjunct in evaluation of chronic mercury neurotoxicity, especially in an epidemiological study. (c) 1995 Wiley-Liss, Inc.
\end{abstract}

Key words: central nervous system function, somatosensory evoked potential, auditory brainstem evoked potential, pattern visual evoked potential, mercury exposure, chloralkali workers

\section{INTRODUCTION}

Acute mercury intoxication following inhalation of large quantities of mercury vapor (elementary mercury) produces adverse effects mainly on the respiratory, renal, and gastrointestinal systems [Marsh, 1985; Foa, 1985]. Acute encephalopathy may also occur [Foa, 1985; Ellenhorn and Barceloux, 1988]. In chronic exposure to elemental mercury, the classic triad of clinical features involves the oral cavity, tremor, and psychological changes. The term "erethism," manifested as insomnia, shyness, emotional lability, memory loss, and loss of appetite, points out the central nervous system (CNS) involvement in this condition [Foa, 1985; Campbell et al., 1992]. As the CNS is the main target organ, biomedical devices to detect hand tremor

\footnotetext{
Department of Neurology, National Taiwan University Hospital, Taiwan, Republic of China (Y.- C.C.). Department of Public Health, Taipei Medical College, Taipei, Taiwan, Republic of China (C.-y.Y.). Graduate Institute of Public Health, National Taiwan University, College of Medicine, Taiwan, Republic of China (J.-D.W.).

Address reprint requests to Yang-Chyuan Chang, MD, Department of Neurology, National Taiwan University Hospital, No. 7, Chung-Shan S. Road, Taipei, Taiwan 100, Taiwan, Republic of China. Accepted for publication March 18, 1994.
} 
[Langolf et al., 1978; Verberk et al., 1986; Roeis et al., 1989] and neuropsychological tests or questionnaire surveillance to assess psychosocial impairment [El-Sadik and El-Dakhakhny, 1970; Smith et al., 1983; Roels et al., 1985] have been applied to the early detection of elemental mercury toxicity on the CNS.

In past decades, clinical electrophysiological studies became popular in the evaluation of human neurotoxicity. Electroencephalographic abnormality is common in mercury-induced toxic encephalopathy, but its utility to detect subclinical or subtle CNS toxicity in mercury workers remains controversial [Foa, 1985]. Evoked potential (EP) study, which is to record the transient potential changes in electric activity within the CNS following stimulation of sensory systems, has been successfully used in demonstrating clinical or subclinical neurotoxicity [Dyer, 1985, 1990; Chang et al., 1990; Mattsson et al., 1992]. However, there were contradictory findings of somatosensory evoked potential (SEP) studies in mercury workers. Lamm and Pratt [1985] reported an acceleration of the somatosensory conduction in the CNS of mercury workers, but Lille et al. [1988] described an increase of the central somatosensory conduction time in their mercury workers. Authors of both reports claimed that their findings could be early signs of CNS toxicity due to mercury.

To clarify the mercury-induced EP changes, we conducted a multimodality EP study on mercury-exposed workers from a chloralkali factory. We also compared EP results in workers with different intensities of mercury exposure.

\section{SUBJECTS AND METHODS Mercury Workers}

A chloralkali factory in the Taipei area stopped production in early 1989. Workers in this factory were mandated to have a thorough physical examination and health consultation before the company was closed. This study was therefore performed 40-70 days after the factory had stood idle. The mercury workers received a complete questionnaire interview, a general physical check-up, laboratory blood tests, and neurological examinations. In taking the medical history, the amount of weekly alcohol consumption, past medical illness, and drug history were carefully recorded. Special attention in the occupational history included years of employment, types of work, hours of daily work, and condition of mercury contamination in the immediate working environment.

\section{Assessment of Exposure}

As this study was performed after the factory had already stopped running, we could not conduct a field investigation to measure the ambient mercury concentration in different workplaces. The intensity of exposure of each worker was therefore retrospectively judged from each individual working history. Those who operated the electrolysis process and worked close to the electrolysis bath were classified as a group with high exposure. Workers who did not participate directly in the process of production but worked in the same factory were classified as workers with low exposure. This group included staff members in the office and the storehouse, transporters, drivers, chemical analyzers, and guards. Workers with medium exposure comprised those in-plant workers who came into contact with the elemental mercury occasionally in their daily work. Workers who recycled the mercury-containing saline and supplied fresh water to the electrolysis bath were included in this group. For each 
chloralkali worker, a blood sample, a sample from 24-hr hour collected urine, and a hair sample cut from the occipital area were sent for determination of the mercury levels.

\section{Analytical Method of Mercury Levels}

Pipette exactly $10 \mathrm{ml}$ of urine sample or $5 \mathrm{ml}$ of blood sample or $100-500 \mathrm{mg}$ of hair sample into a Sjostrandis digestion apparatus. Add ultra pure nitric acid $5 \mathrm{ml}$ and sulfuric acid $2 \mathrm{ml}$ as the digestion solution and $1-3 \mathrm{ml}$ of 5\% potassium permanganate as the oxidizing agent. Let the above solution be boiled and reflexed until the digestion is complete and the purple color of potassium permanganate persists after cooling. Then, hydroxylammonium chloride solution is added with constant swirling until the solution becomes colorless and clear. Dilute the solution to $50 \mathrm{ml}$ and analyze it by generating cold vapor mercury with stannous chloride as the reducing agent, and obtain the atomic absorption sepctrometry (Model IL VIDEO 12, Instrumental Laboratory) at wave length $253.7 \mathrm{~nm}$.

\section{EP Study}

The methods used to record EPs to pattern visual, auditory brainstem, and somatosensory stimulation in this clinical neurophysiology laboratory have been published elsewhere [Chang et al., 1990]. All the EPs were recorded with a Pathfinder II machine (Nicolet). Pattern visual evoked potentials (pVEPs) to checkerboard were recorded at $\mathrm{Oz}-\mathrm{Cz}$ (International 10-20 system), with check size subtending $1^{\circ}, 30^{\prime}$, $15^{\prime}$, and $7.5^{\prime}$ of the visual angle at a reversal rate of $1.88 / \mathrm{s}$. The analysis time was $250 \mathrm{~ms}$ and the number of responses in averaging for each trial was 256 . The $\mathrm{N} 1$ $(\mathrm{N} \overline{75}), \mathrm{P} 1(\mathrm{P} \overline{100})$, and $\mathrm{N} 2(\mathrm{~N} \overline{135})$ peak latencies of the pVEP from a visual angle of $30^{\prime}$ were taken. The N1-P1 and P1-N2 interpeak amplitudes were also measured.

Brainstem auditory evoked potentials (BAEP) were recorded at $\mathrm{A} 2-\mathrm{Cz}$ or A1$\mathrm{Cz}$. The auditory stimulation consisted of ipsilateral clicks of $0.1 \mathrm{~ms}$ duration at a delivery rate of $11.1 \mathrm{~Hz}$. The auditory stimulus in both rarefaction and condensation polarities was set at an intensity of $60 \mathrm{~dB}$ above the audible threshold for each subject. The analysis time was $10 \mathrm{~ms}$ and 2,048 responses were averaged for each trial. Out of the seven positive peaks within $10 \mathrm{~ms}$, the absolute peak latencies of wave I, III, and $\mathrm{V}$ were measured for data analysis.

SEP to median nerve stimulation were studied. The scalp SEP was taken at the contralateral central region of the scalp $\left(\mathrm{C}^{\prime}\right.$ or $\left.\mathrm{C}^{\prime}\right)$; neck SEP, at the seventh cervical spinous process; and brachial nerve action potentials (NAP), at the ipsilateral Erb's point. Square wave pulse electric stimulation of $0.1 \mathrm{~ms}$ duration was applied to the median nerve at the wrist. The stimulation was given at a rate of $2.7 \mathrm{~Hz}$ and its intensity was adjusted to the minimal current for eliciting visible thumb twitches. The analysis time was $50 \mathrm{~ms}$ and 512 responses were averaged for each trial. The absolute latencies of the $\mathrm{N} 1(\mathrm{~N} \overline{20})$ component of scalp SEP, and of the $\mathrm{N} \overline{13}$ peak of neck SEP, and of the negative peak of brachial NAP were measured. Central conduction time (CCT) was defined as the time difference between the scalp SEP (N1) and the neck SEP (Ni3) latencies.

From the stored pVEP and BAEP data in the laboratory, EP findings of two individually matched male normal subjects with similar age (within \pm 2 years) and same side of stimulation for each mercury worker were selected. The arithmetic mean 
of corresponding EP data from these two subjects constituted the normal control group. To select the individually matched controls for SEP study, both the age and the body height (within $\pm 2 \mathrm{~cm}$ ) were taken into consideration. All the subjects underwent EP studies at the same clinical neurophysiology laboratory by the same technologists with the same EP machine. To minimize bias from side-to-side differences, EP data from the right and the left side were calculated and analyzed separately.

As EP latency values have been found to be normally distributed within the population [Chabot and John, 1986] and all the possible variables able to influence EP findings had been well controlled in this study, we therefore applied paired t-test to examine the significance of latency difference in EP findings between the mercury workers and controls. Because of the nongaussian distribution of EP amplitude values [Celesia, 1985], Mann-Whitney's test was used to examine the significance of amplitude difference. Within three groups of mercury workers with different exposure intensity, one-way analysis of variance (ANOVA) test was used to examine significance levels of the discrepancy of EP results between the mercury workers and matched controls. These discrepancies between any two mercury-exposed groups were further evaluated with Scheffe's procedure.

\section{RESULTS}

\section{Mercury Levels and Intensity of Mercury Exposure}

The chloralkali factory had employed 41 workers. Having no subjective discomfort, two workers refused to take part in this health-screening project. An additional 13 workers, who already had new jobs, did not receive the time-consuming EP study. Hence, 26 workers from this chloralkali plant underwent the complete series of questionnaire interview, physical and neurological examinations, routine laboratory blood tests, determination of mercury levels, and EP study. All of them were male and their age ranged from 33 to 54 years with a mean of 43.3 years. They had done the same type of work at the same workplace for 9 months to 26 years, with a mean of 12 years. Their mean body height was $166 \mathrm{~cm}$ with a standard deviation of $5.4 \mathrm{~cm}$. On routine neurological examinations, no remarkable neurological abnormalities, including hand tremors, were found.

Among them, 10 workers were classified into the group with high mercury exposure, 5 with medium mercury exposure, and 11 with low mercury exposure. Table I shows the age, body height, various mercury levels, and mercury output in 24-hr urine in each group. The 24-hr mercury output in urine or the mercury level in the hair and urine were higher in workers with high exposure. The difference of these measurements between medium and low exposure groups was not statistically significant. There was no significant difference of the blood mercury level among these three groups of chloralkali workers.

\section{Findings of EP}

In Tables II-IV, pVEP findings from the right eye, BAEP findings from the right ear, and SEP findings from the right median nerve are listed. Although not shown in the tables, EP data from the left side stimulation had the same patterns of differences between the mercury workers and controls.

Table II lists pVEP findings in mercury workers and in the corresponding normal controls. There was no significant difference of $\mathrm{N} 1, \mathrm{P} 1$, or $\mathrm{N} 2$ peak latency 
TABLE I. Age, Body Height, and Mercury Levels in Chloralkali Workers With Different Intensities of Mercury Exposure

\begin{tabular}{lcccc}
\hline & $\begin{array}{c}\text { High } \\
\text { exposure } \\
\text { group } \\
(\mathrm{n}=10)\end{array}$ & $\begin{array}{c}\text { Medium } \\
\text { exposure } \\
\text { group } \\
(\mathrm{n}=5)\end{array}$ & $\begin{array}{c}\text { Low } \\
\text { exposure } \\
\text { group } \\
(\mathrm{n}=11)\end{array}$ & $\begin{array}{c}\text { Total } \\
\text { workers } \\
(\mathrm{n}=26)\end{array}$ \\
\hline $\begin{array}{l}\text { Age (years) } \\
\text { Body height }(\mathrm{cm})\end{array}$ & $44.8 \pm 6.2$ & $37.6 \pm 5.8$ & $44.5 \pm 6.9$ & $43.3 \pm 6.9$ \\
Mercury level & $163.0 \pm 4.4$ & $169.2 \pm 5.3$ & $167.4 \pm 5.1$ & $166.0 \pm 5.4$ \\
$\quad$ Hair $(\mu \mathrm{g} / \mathrm{g})$ & $53.9 \pm 34.6$ & $9.7 \pm 6.7$ & $4.9 \pm 1.1$ & $24.7 \pm 32.2$ \\
$\quad$ Blood $(\mu \mathrm{g} / \mathrm{dL})$ & $3.0 \pm 0.62$ & $2.7 \pm 0.7$ & $2.7 \pm 0.8$ & $2.8 \pm 0.7$ \\
$\quad \begin{array}{l}\text { Urine }(\mu \mathrm{g} / \mathrm{L}) \\
\quad \text { Urine level as } \mu \mathrm{g} / \mathrm{g} \text { creatinine }\end{array}$ & $55.6 \pm 26.1$ & $18.1 \pm 12.8$ & $16.8 \pm 7.3$ & $28.1 \pm 22.9$ \\
24-hr mercury output & $597 \pm 283$ & $266 \pm 138$ & $142 \pm 68$ & $358 \pm 286$ \\
in urine $(\mu \mathrm{g})$ & $70.2 \pm 46.2$ & $27.5 \pm 19.2$ & $19.4 \pm 11.8$ & $40.5 \pm 39.5$ \\
\hline
\end{tabular}

between any group of mercury workers and the corresponding normal control group. However, the mean N1-P1 interpeak amplitude was significantly larger in mercury workers as a whole group and in workers with high mercury exposure than in the corresponding normal controls. With one-way ANOVA and Scheffe's procedures, this difference was found due to an amplitude increase in the group with high exposure.

Table III shows findings of BAEP study. The wave I and wave III latencies did not differ significantly between mercury workers and control groups. In workers with high mercury exposure, however, there was a significant delay of wave $V$ latency leading to a prolongation of I-V interpeak latencies. With one-way ANOVA and Scheffe's procedures, the prolongation of wave $\mathrm{V}$ latency and $\mathrm{I}-\mathrm{V}$ interpeak latency was also found only in workers with high exposure.

In Table IV, SEP findings from the median nerve are shown. There was no signficant difference in both the brachial NAP and neck SEP latencies between mercury workers and corresponding normal controls. Significantly prolonged scalp SEP latency and CCT were seen in the workers with high mercury exposure (examined with paired t-, one-way ANOVA, and Scheffe's tests).

\section{DISCUSSION}

Workers in a chloralkali factory are subject to exposure to sodium hydroxide, chlorine, hydrogen chloride, and mercury vapor. The former three substances are severe irritants to the respiratory system, eyes, skin, and mucous membranes. The nervous system is not their primary toxic target organ. In contrast, long-term exposure to mercury vapor can cause a variety of neurological manifestations including short-term memory deficits, poor concentration, decreased psychomotor skills, parkinsonian state, dysarthria, and a syndrome resembling amyotrophic lateral sclerosis [Campbell et al., 1992]. Subclinical reductions of peripheral nerve conduction have also been observed [Albers et al., 1982; Levine et al., 1982; Singer et al., 1987]. We therefore believe that EP changes in the present chloralkali workers would be a result of chronic exposure to mercury vapor, not to other chemical substances. These EP 
TABLE II. Findings of pVEP From the Right Eye in Chloralkali Workers With Different Intensity of Mercury Exposure*

\begin{tabular}{|c|c|c|c|c|c|}
\hline & $\begin{array}{c}\text { N1 } \\
\text { latency } \\
\text { (ms) }\end{array}$ & $\begin{array}{c}\text { P1 } \\
\text { latency } \\
\text { (ms) }\end{array}$ & $\begin{array}{c}\mathrm{N} 2 \\
\text { latency } \\
\text { (ms) }\end{array}$ & $\begin{array}{c}\text { N1-P1 } \\
\text { interpeak } \\
\text { amplitude } \\
(\mu V)^{\mathbf{a}}\end{array}$ & $\begin{array}{c}\text { P1-N2 } \\
\text { interpeak } \\
\text { amplitude } \\
(\mu \mathrm{V})\end{array}$ \\
\hline $\begin{array}{l}\text { All mercury } \\
\text { workers }(n=26)\end{array}$ & $\begin{array}{c}72.8 \pm 4.7 \\
(74.3 \pm 2.6)\end{array}$ & $\begin{array}{c}95.7 \pm 3.6 \\
(97.1 \pm 2.6)\end{array}$ & $\begin{array}{c}126.8 \pm 7.1 \\
(127.8 \pm 5.0)\end{array}$ & $\begin{array}{r}6.08 \pm 2.46^{b} \\
(4.90 \pm 1.53)\end{array}$ & $\begin{array}{c}7.92 \pm 3.24 \\
(6.79 \pm 2.26)\end{array}$ \\
\hline $\begin{array}{l}\text { High exposure } \\
\text { group }(n=10)\end{array}$ & $\begin{array}{c}72.9 \pm 5.5 \\
(74.4 \pm 3.0)\end{array}$ & $\begin{array}{c}94.6 \pm 2.9 \\
(97.1 \pm 3.1)\end{array}$ & $\begin{array}{c}126.7 \pm 6.2 \\
(128.2 \pm 5.9)\end{array}$ & $\begin{array}{r}6.47 \pm 2.49^{b} \\
(4.99 \pm 1.84)\end{array}$ & $\begin{array}{c}8.07 \pm 2.89 \\
(6.79 \pm 2.68)\end{array}$ \\
\hline $\begin{array}{l}\text { Medium exposure } \\
\text { group }(n=5)\end{array}$ & $\begin{array}{c}73.0 \pm 3.2 \\
(75.5 \pm 1.5)\end{array}$ & $\begin{array}{c}95.5 \pm 4.8 \\
(96.6 \pm 1.8)\end{array}$ & $\begin{array}{c}127.0 \pm 6.2 \\
(126.5 \pm 5.1)\end{array}$ & $\begin{array}{c}5.74 \pm 2.87 \\
(5.39 \pm 1.72)\end{array}$ & $\begin{array}{c}7.35 \pm 2.84 \\
(6.95 \pm 2.75)\end{array}$ \\
\hline $\begin{array}{l}\text { Low exposure } \\
\text { group }(n=11)\end{array}$ & $\begin{array}{c}72.7 \pm 4.9 \\
(73.8 \pm 2.6)\end{array}$ & $\begin{array}{c}96.9 \pm 3.7 \\
(97.3 \pm 2.6)\end{array}$ & $\begin{array}{c}126.7 \pm 8.8 \\
(128.1 \pm 4.2)\end{array}$ & $\begin{array}{c}5.86 \pm 2.36 \\
(4.57 \pm 1.19)\end{array}$ & $\begin{array}{c}8.04 \pm 3.68 \\
(6.70 \pm 1.60)\end{array}$ \\
\hline
\end{tabular}

* Data in parentheses are pVEP findings from the corresponding individually matched normal controls. ${ }^{a}$ The discrepancy of N1-P1 amplitudes between mercury workers and controls within three worker groups is $\mathbf{F}=3.60$ and $\alpha<0.05$.

'The significance level of difference between normal controls and mercury workers is $p<0.05$.

TABLE III. Findings of BAEP From the Right Ear in Chloralkali Workers With Different Intensity of Mercury Exposure*

\begin{tabular}{|c|c|c|c|c|}
\hline & $\begin{array}{c}\text { I latency } \\
(\mathrm{ms})\end{array}$ & $\begin{array}{l}\text { III latency } \\
\text { (ms) }\end{array}$ & $\begin{array}{l}\text { V Jatency } \\
(\mathrm{ms})^{\mathrm{a}}\end{array}$ & $\begin{array}{c}\mathrm{I}-\mathrm{V} \\
\text { interpeak } \\
\text { latency } \\
(\mathrm{ms})^{\mathrm{b}}\end{array}$ \\
\hline $\begin{array}{l}\text { All mercury } \\
\text { workers }(n=26)\end{array}$ & $\begin{array}{c}1.55 \pm 0.09 \\
(1.55 \pm 0.05)\end{array}$ & $\begin{array}{c}3.76 \pm 0.16 \\
(3.74 \pm 0.10)\end{array}$ & $\begin{array}{c}5.76 \pm 0.16 \\
(5.69 \pm 0.10)\end{array}$ & $\begin{array}{c}4.20 \pm 0.19 \\
(4.14 \pm 0.09)\end{array}$ \\
\hline $\begin{array}{l}\text { High exposure } \\
\text { group }(n=10)\end{array}$ & $\begin{array}{c}1.53 \pm 0.08 \\
(1.57 \pm 0.07)\end{array}$ & $\begin{array}{c}3.74 \pm 0.17 \\
(3.73 \pm 0.09)\end{array}$ & $\begin{array}{r}5.80 \pm 0.12^{\mathrm{c}} \\
(5.68 \pm 0.11)\end{array}$ & $\begin{array}{r}4.26 \pm 0.16^{c} \\
(4.11 \pm 0.10)\end{array}$ \\
\hline $\begin{array}{l}\text { Medium exposure } \\
\text { group }(n=5)\end{array}$ & $\begin{array}{c}1.55 \pm 0.07 \\
(1.53 \pm 0.04)\end{array}$ & $\begin{array}{c}3.76 \pm 0.17 \\
(3.73 \pm 0.11)\end{array}$ & $\begin{array}{c}5.74 \pm 0.17 \\
(5.69 \pm 0.08)\end{array}$ & $\begin{array}{c}4.18 \pm 0.13 \\
(4.16 \pm 0.07)\end{array}$ \\
\hline $\begin{array}{l}\text { Low exposure } \\
\quad \text { group }(n=11)\end{array}$ & $\begin{array}{c}1.57 \pm 0.11 \\
(1.53 \pm 0.03)\end{array}$ & $\begin{array}{c}3.78 \pm 0.16 \\
(3.76 \pm 0.10)\end{array}$ & $\begin{array}{c}5.73 \pm 0.18 \\
(5.69 \pm 0.11)\end{array}$ & $\begin{array}{c}4.15 \pm 0.24 \\
(4.17 \pm 0.10)\end{array}$ \\
\hline
\end{tabular}

*Data in parentheses are BAEP findings from the corresponding individually matched normal controls. ${ }^{a}$ The discrepancy of wave $V$ latency between mercury workers and controls within three worker groups is $F=10.56$ and $\alpha<0.001$.

${ }^{\mathrm{b}}$ The discrepancy of I-V interpeak latency between mercury workers and controls within three worker groups is $F=13.47$ and $\alpha<0.001$.

${ }^{\mathrm{c}}$ The significant level of difference between normal controls and mercury workers is $\mathrm{p}<0.05$.

changes were clearly demonstrated in mercury workers in general and in workers with high mercury exposure particularly.

As this study was conducted 40 days after the chloralkali workers had already left their works, their mercury levels must be underestimates. The body mercury levels in each group of mercury workers (Table I) could imply that the assessment of mercury exposure in the present study was adequate.

In a SEP study from the median nerve on 15 chloralkali workers, Lamm and Pratt [1985] reported a delay in nerve ending conduction times at the periphery and an acceleration of somatosensory conduction from brainstem to cortex. Lille et al. 
TABLE IV. Findings of SEP From the Right Median Nerve in Chloralkali Workers With Different Severity of Mercury Exposure*

\begin{tabular}{|c|c|c|c|c|}
\hline & $\begin{array}{c}\text { Scalp SEP } \\
\text { latency } \\
(\mathrm{ms})^{\mathrm{a}}\end{array}$ & $\begin{array}{c}\text { Neck SEP } \\
\text { latency } \\
\text { (ms) }\end{array}$ & $\begin{array}{c}\text { Brachial } \\
\text { NAP } \\
\text { latency } \\
\text { (ms) }\end{array}$ & $\begin{array}{c}\text { Central } \\
\text { conduction } \\
\text { time } \\
(\mathrm{ms})^{\mathrm{b}}\end{array}$ \\
\hline $\begin{array}{l}\text { All mercury } \\
\quad \text { workers }(n=26)\end{array}$ & $\begin{array}{r}19.47 \pm 0.73^{c} \\
(19.10 \pm 0.60)\end{array}$ & $\begin{array}{c}13.21 \pm 0.61 \\
(13.28 \pm 0.49)\end{array}$ & $\begin{array}{c}9.34 \pm 0.50 \\
(9.36 \pm 0.42)\end{array}$ & $\begin{array}{r}6.25 \pm 0.56^{d} \\
(5.82 \pm 0.26)\end{array}$ \\
\hline $\begin{array}{l}\text { High exposure } \\
\text { group }(n=10)\end{array}$ & $\begin{array}{r}19.60 \pm 0.57^{\mathrm{c}} \\
(19.10 \pm 0.72)\end{array}$ & $\begin{array}{c}13.08 \pm 0.48 \\
(13.36 \pm 0.63)\end{array}$ & $\begin{array}{c}9.19 \pm 0.34 \\
(9.32 \pm 0.56)\end{array}$ & $\begin{array}{r}6.51 \pm 0.38^{e} \\
(5.74 \pm 0.24)\end{array}$ \\
\hline $\begin{array}{l}\text { Medium exposure } \\
\text { group }(\mathrm{n}=5)\end{array}$ & $\begin{array}{c}19.44 \pm 1.19 \\
(19.10 \pm 0.63)\end{array}$ & $\begin{array}{c}13.26 \pm 0.84 \\
(13.08 \pm 0.25)\end{array}$ & $\begin{array}{c}9.40 \pm 0.62 \\
(9.33 \pm 0.17)\end{array}$ & $\begin{array}{c}6.18 \pm 0.62 \\
(6.01 \pm 0.44)\end{array}$ \\
\hline $\begin{array}{l}\text { Low exposure } \\
\quad \text { group }(n=11)\end{array}$ & $\begin{array}{c}19.34 \pm 0.70 \\
(19.10 \pm 0.52)\end{array}$ & $\begin{array}{c}13.30 \pm 0.62 \\
(13.31 \pm 0.42)\end{array}$ & $\begin{array}{c}9.45 \pm 0.53 \\
(9.41 \pm 0.37)\end{array}$ & $\begin{array}{c}6.04 \pm 0.63 \\
(5.79 \pm 0.24)\end{array}$ \\
\hline
\end{tabular}

*Data in parentheses are SEP findings from the corresponding individually matched controls.

${ }^{a}$ The discrepancy of scalp SEP latency between mercury workers and controls within three worker groups is $F=4.24$ and $\alpha<0.05$.

${ }^{b}$ The discrepancy of central conduction time between mercury workers and controls within three worker groups is $\mathrm{F}=21.24$ and $\alpha<0.001$.

The significant levels of difference between normal controls and mercury workers are: ${ }^{c} p<0.05,{ }^{d} p<$ 0.01 , and ${ }^{\mathrm{e}} \mathrm{p}<0.001$.

[1988] perfomed a multimodality EP study on five mercury workers and four accidentally mercury contaminated subjects. In the pVEP study, they found a shortening of N1 latency and an increase of P1-N2 interpeak amplitude. The somatosensory CCT calculated from the SEP findings by stimulation of the posterior tibial nerve was prolonged. An increase of SEP amplitude was also observed. However, authors of these two studies did not correlate their EP findings with the levels of mercury exposure or biological assessments of body mercury levels.

The significant EP findings in the present chloralkali workers were increased interpeak amplitudes of pVEP, prolonged wave I-V interpeak latencies of BAEP, and delayed CCTs of SEP. Decrease in amplitudes and increase in absolute peak latencies, or interpeak latencies, or conduction times are generally considered as abnormal findings in clinical evaluation of patients' EP data [Spehlmann, 1985]. Such kinds of EP abnormalities are also commonly accepted as CNS effects of neurotoxic substances [Dyer, 1990; Chang et al., 1990; Mattsson et al., 1992]. Although EP changes indicating accelerated neural conductions in the CNS are clinically not considered as abnormal findings, such EP findings have already been mentioned in workers exposed to inorganic mercury [Lamm and Pratt, 1985]. Dyer [1986] also mentioned an increase in EP amplitude in animals and workers exposed to certain toxins.

Neural conductivity in the sensory pathways and synaptic transmissibility at the nerve terminals influence the EP latency, while an EP amplitude is related to the number of neurons excited by the repetitive stimulation. As wave I of BAEP generating from the auditory nerve and wave $V$ from the neural structures at the midbrain [Mattsson et al., 1992], prolongation of BAEP I-V interpeak latency would indicate a toxic effect of mercury vapor on the brainstem. In view of the generating sites of neck and scalp SEPs [Mattsson et al., 1992], abnormal CCTs in our workers could 
represent a mercury effect on the neural pathway from the cervical cord to the thalamus or cortex. Although the anatomical structures to generate pVEP are less well known [Mattsson et al., 1992], the present pVEP findings could suggest a CNS effect of mercury vapor. However, we cannot precisely point out the detailed neural structures related to these EP abnormalities.

Toxic damage to nerve connections and white matter in the CNS would cause slowing of neural conduction and prolongation of EP latencies. Toxin-induced reduction in the number of excited neurons or loss of firing synchrony would result in an amplitude decrease in EP study [Mattsson et al., 1992]. Thus, mercury vaporinduced conduction impairment in the CNS, as revealed by the present EP study, is plausible. However, these basic neurophysiological principles are not adequate to explain why mercury could also induce an acceleration of neural conductions and an increase in EP amplitudes. Dyer [1986] and Lille et al. [1988] proposed that impairment of inhibitory mechanisms leading to neuronal hyperexcitability could cause this kind of EP changes. Lamm and Pratt [1985] also suggested that there was a mercuryinduced primary damage in synaptic inhibitory mechanisms causing accelerated neural conductions. Moreover, Lille et al. [1988] proposed that an increase of EP amplitude could be an earlier sign of neurotoxicity and should not be specific to certain toxins. At higher concentrations of toxic agents, latency increase and amplitude decrease would follow. Their hypothesis, which could be useful to explain why there are contradictory EP findings in different studies, needs further confirmation.

Relationships between mercury levels and clinical manifestations have been extensively investigated in mercury exposure or intoxication [Rosenman et al., 1986; Ellenhorn and Barceloux, 1988]. The blood mercury level is the best measure of recent exposure but has no good correlations with the clinical features in chronic intoxication. On the contrary, Rosenman et al. [1986] reported that neuropsychological symptoms and other toxic manifestations had good correlations with urinary mercury levels or 24-hr urinary mercury outputs. We could not find significant correlations between EP abnormalities and body mercury levels in the present study, but these EP changes were mainly seen in mercury workers with high exposure.

In conclusion, we confirmed that chronic exposure to mercury vapor would cause EP changes indicating CNS neurotoxicity, especially in workers with high exposure. A multimodality EP study is a useful adjunct to evaluation of chronic mercury neurotoxicity, especially in an epidemiological study.

\section{REFERENCES}

Albers JW, Cavender GD, Levine SP, Langolf GD (1982): Asymptomatic sensorimotor polyneuropathy in workers exposed to elemental mercury. Neurology 32:1168-1174.

Campbell D, Gonzales M, Sullivan JB (1992): Mercury. In Sullivan JB, Krieger GR (eds): "Hazardous Materials Toxicology." Baltimore: Williams \& Wilkins, pp 824-833.

Celesia GG (1985): Visual evoked responses. In Owen JH, Davis H (eds): "Evoked Potential Testing." Orlando: Grune \& Stratton, p 16.

Chabot RJ, John ER (1986): Normative evoked potential data. In Lopes da Silva FH, Storm van Leeuwen W, Remond A (eds): "'Handbook of Electroencephalography and Clinical Neurophysiology, Revised Series, Volume 2-Clinical Applications of Computer Analysis of EEG and other Neurophysiological Signals." Amsterdam, New York, Oxford: Elsevier, p 263.

Chang YC, Lin HN, Deng HC (1990): Subclinical lithium neurotoxicity: Correlation of neural conduction abnormalities and serum lithium level in manic-depressive patients with lithium treatment. Acta Neurol Scand 82:82-86. 
Dyer RS (1985): The use of sensory evoked potentials in toxicology. Fund Appl Toxicol 5:24-40.

Dyer RS (1986): The interactions of behavior and neurophysiology. In Annau Z (ed): "Neurobehavioral Toxicology." Victoria, Australia: Edward Arnold, pp 193-213.

Dyer RS (1990): Evoked potentials: Physiological methods with human applications. In Johnson BL, Anger WK, Durao A, Xintaras C (eds): "Advances in Neurobehavioral Toxicology." Chelsea, MI: Lewis Publishers, pp 165-174.

Ellenhorn MJ, Barceloux DG (1988): “Medical Toxicology.” New York: Elsevier, pp 1048-1053.

El-Sadik YM, El-Dakhakhny A-A (1970): Effects of exposure of workers to mercury at a sodium hydroxide producing plant. Am Ind Hyg Assoc J 31:705-710.

Foa V (1985): Neurotoxicity of elemental mercury: Occupational aspects. In Blum K, Manzo L (eds): "Drug and Chemical Toxicology, Vol 3, Neurotoxicology." New York, Basel: Marcel Dekker Inc, pp 323-337.

Lamm O, Pratt H (1985): Subclinical effects of exposure to inorganic mercury revealed by somatosensory-evoked potentials. Eur Neurol 24:237-243.

Langolf GD, Chaffin DB, Henderson R, Whittle HP (1978): Evaluation of workers exposed to elemental mercury using quantitative tests of tremor and neuromuscular functions. Am Ind Hyg Assoc J 39:976-984.

Levine SP, Cavender GD, Langolf GD, Albers JW (1982): Elemental mercury exposure: Peripheral neurotoxicity. Br J Ind Med 39:136-139.

Lille F, Hazemann P, Garnier R, Dally S (1988): Effects of lead and mercury intoxications on evoked potentials. Clin Toxicol 26:103-116.

Marsh DO (1985): The neurotoxicity of mercury and lead. In O'Donoghue JL (ed): “Neurotoxicity of Industrial and Commercial Chemicals." Boca Raton: CRC Press, pp 159-163.

Mattsson JL, Boyes WK, Ross JF (1992): Incorporating evoked potentials into neurotoxicity test schemes. In Tilson HA, Mitchell CL (eds): "Neurotoxicology, Target Organ Toxicology Series." New York: Raven Press, pp 125-145.

Roels H, Gennart J-P, Lauwerys R, Buchet J-P, Malchaire J, Bernard A (1985): Surveillance of workers exposed to mercury vapor: Validation of a previously proposed biological treshold limit value for mercury concentration in urine. Am J Ind Med 7:45-71.

Roels H, Abdeladim S, Braun M, Malchaire J, Lauwerys R (1989): Detection of hand tremor in workers exposed to mercury vapor: A comparative study of three methods. Environ Res 49:152-165.

Rosenman KD, Valciukas JA, Glickman L, Meyers BR, Cinotti A (1986): Sensitive indicators of iorganic mercury toxicity. Arch Environ Health 41:208-215.

Singer R, Valciukas JA, Rosenman KD (1987): Peripheral neurotoxicity in workers exposed to inorganic mercury compounds. Arch Environ Health 42:181-184.

Smith PJ, Langolf GD, Goldberg J (1983): Effects of occupational exposure to elemental mercury on short term memory. Br J Ind Med 40:413-419.

Spehlmann R (1985): “Evoked Potential Primer." Boston: Butterworth Publishers, pp 68-70.

Verberk MM, Salle HJA, Kemper CH (1986): Tremor in workers with low exposure to metallic mercury. Am Ind Hyg Assoc J 47:559-562. 